\title{
Padrões de especialização e fluxos de comércio internacional dos países integrantes do grupo BRIC no período 2000-2012*
}

\author{
Clésio Lourenço Xavier **
}

Daniela Fernanda Yamane ${ }^{* * *}$

Recebido: 04/03/2014 Versão Revisada (entregue): 06/08/2014 Aprovado: 14/08/2014

\section{RESUMO}

O trabalho tem por objetivo caracterizar, quantitativa e qualitativamente, a evolução dos fluxos de comércio dos países integrantes do grupo BRIC (Brasil, Rússia, Índia e China) nos anos 2000. Para isso, analisam-se o crescimento, a composição relativa e o saldo comercial dos fluxos de comércio do BRIC e calculam-se os indicadores de comércio exterior (market-share, vantagens comparativas reveladas e índice de contribuição ao saldo comercial). Os resultados obtidos mostraram que, por um lado, o Brasil e a Rússia não apenas mantiveram um padrão de especialização rígido, com continuidade daquele verificado no início dos anos 2000, como também se aprofundaram neste padrão, com aumento do dinamismo em produtos primários e intensivos em recursos naturais (eficiência ricardiana). Por outro lado, a Índia e, principalmente, a China apresentaram modificaçôes no período, convergindo para um padrão de especialização pautado em produtos de maior valor agregado e com maior diversificação (eficiência em crescimento e eficiência schumpeteriana).

PalaVras-CHAVE | Padrões de Especialização; Fluxos de Comércio Internacional; BRIC

CÓdigo JEL | F14

* Os autores agradecem ao apoio financeiro recebido da Capes.

** Pesquisador Bolsista de Produtividade do CNPq - Conselho Nacional de Desenvolvimento Científico e Tecnológico. Universidade Federal de Uberlândia - UFU (MG), Brasil. E-mail: clesio@ie.ufu.br.

*** Universidade Federal de Uberlândia (UFU), Uberlândia (MG), Brasil. E-mail: daniela_yamane@yahoo.com.br. 


\title{
Patterns of specialization and international trade flows of BRIC countries in the period 2000-2012
}

\begin{abstract}
This work aims to monitor and characterize quantitatively and qualitatively, the evolution of trade flows of the countries members of BRIC in the 2000s. For this, it has been analyzed the growth, the relative composition and the trade balance of the commercial flows of BRIC, and calculated the indicators of external trade (Market-Share, Revealed Comparative Advantages and Index of Contribution to the Trade Balance) and the obtained results were that, on the one hand, Brazil and Russia not only maintained a pattern of rigid specialization, keeping with the existing pattern in the early 2000s, but also deepened this pattern, with an increase in the dynamics of primary products and intensives in natural resources. On the other hand, India and mainly China showed changes in the period, converging to a pattern of specialization based on products with higher added value and greater diversification.
\end{abstract}

KEYwORDS | Patterns of Specialization; International Trade Flows; BRIC

JEL-CODE | F14 


\section{Introdução}

Desde os anos 1980, o cenário mundial vem sendo caracterizado pelo acirramento da concorrência internacional e pelo deslocamento das plantas de produção para países com menores custos de mão de obra e matéria-prima, favorecendo a fragmentação de cadeias de produção em determinados setores. Na década de 2000, os conceitos de competitividade externa e desempenho econômico estiveram mais intensamente correlacionados, sendo que nesta década China, Índia e outros paises em desenvolvimento buscaram e tiveram um reposicionamento no mercado internacional, alterando suas trajetórias de crescimento de longo prazo (CARVALHO, 2010).

O período de 2003 a 2008 foi caracterizado por um ciclo de expansão favorável na economia mundial, a partir do alto crescimento do PIB global, da baixa inflação, da retomada do dinamismo em regiōes como América Latina, África, Leste Europeu, Japão e Alemanha e da melhoria das contas externas e finanças públicas dos países em desenvolvimento. Neste momento, surgiu uma nova realidade, em que países emergentes, como China, Índia, Rússia e Brasil, entre outros, atingiram peso igual ou superior aos das economias centrais na renda mundial, nos fluxos de comércio e na determinação do ritmo de expansão (CUNHA, 2011).

Na primeira década do século XXI, com o aumento da demanda mundial por commodities, em especial da China, forte pressão competitiva foi exercida sobre as economias industrializadas e em desenvolvimento. A elevação da demanda por matérias-primas e energia teve efeitos sobre a distribuição da oferta e dos preços das commodities, impactando sobre países produtores e consumidores. Com a elevação da demanda e dos preços das commodities, os países da América Latina beneficiaram-se por serem grandes exportadores destes produtos, com ampliação do fluxo de comércio e dos investimentos.

Diante destas mudanças na economia mundial, torna-se relevante acompanhar as possíveis alterações no padrão de especialização dos países do BRIC nos anos 2000 , sendo que a escolha destes países está relacionada ao seu desempenho no cenário internacional nos primeiros anos do século XXI, além da sua maior resistência diante da crise financeira internacional de 2008.

Assim, o objetivo deste trabalho é verificar a evolução do padrão de especialização dos países do BRIC no período 2000-2012, a partir de uma análise não apenas quantitativa, mas também qualitativa dos fluxos de comércio, por meio da definição de eficiência no comércio (eficiência ricardiana, eficiência em crescimento e eficiência 
schumpeteriana). A questão que se busca responder é se ocorreram transformações nos padrões de comércio destes países no período e qual tipo de eficiência no comércio internacional relaciona-se com tais alterações.

O trabalho está estruturado em duas seções, além desta introdução e das considerações finais. Na segunda seção, tomando como ponto de partida a ideia de que a caracterização de um padrão de especialização requer a quantificação e a qualificação dos fluxos de comércio, são discutidos três tipos de eficiência - a eficiência ricardiana, a eficiência em crescimento e a eficiência schumpeteriana - e apresentam-se as notas metodológicas. Na terceira, é caracterizado o padrão de especialização dos países do BRIC entre 2000 e 2012. Para isso, são calculados o crescimento, a composição relativa e o saldo comercial dos fluxos comerciais do BRIC, além de alguns indicadores de comércio exterior.

\section{Noções de eficiência e padrões de especialização comercial e notas metodológicas}

Esta seção aborda os padrões de especialização, a partir do conceito de eficiência nos fluxos de comércio exterior, sendo importante na medida em que permite a caracterização da evolução do padrão de especialização do BRIC na primeira década do século XXI. De acordo com Martins (2004), existem na literatura algumas possibilidades envolvendo a noção de eficiência presente nos fluxos de comércio exterior.

Em primeiro lugar, tem-se a eficiência ricardiana, referenciada na literatura convencional, em que o padrão de especialização produtivo e comercial do país é determinado pela abundância ou escassez relativa dos fatores de produção, podendo ser aferida por meio da vantagem comparativa revelada de custos na produção de um bem se o custo de oportunidade da produção em termos de outros bens é mais baixo do que em outros países.

Em segundo lugar, a eficiência em crescimento remete à teoria kaldoriana e está relacionada à intensidade da renda da composição das exportações de um país (DOSI; PAVITT; SOETE, 1990). Uma estrutura exportadora com produtos de alta elasticidade-renda indicaria um padrão de especialização mais eficiente e poderia gerar maiores taxas de crescimento econômico, sendo que os diferenciais na elasticidade-renda das exportações originam-se nas assimetrias tecnológicas e na habilidade inovativa dos agentes econômicos, atuando na redefinição dos padrões de demanda. Assim, quanto mais os produtos de determinado país forem demandados 
internacionalmente em razão do crescimento da renda do resto do mundo, maiores serão as oportunidades para o país crescer economicamente.

Em terceiro lugar, mas não menos importante, a literatura ressalta a eficiência schumpeteriana, que é uma sofisticação da contribuição de Kaldor, conferindo um caráter endógeno e dinâmico ao progresso técnico. A eficiência schumpeteriana estabelece que o padrão de especialização de um país depende do grau de oportunidade, ou seja, das trajetórias de desenvolvimento tecnológico, da apropriabilidade dos retornos econômicos relacionados à inovação, dificultando as possibilidades de imitação e obtendo lucros monopólicos, e da cumulatividade tecnológica, pois o padrão de especialização atual condiciona o padrão de especialização futuro, proporcionando resultados positivos ou negativos para o crescimento econômico e para o bem-estar.

Diante dessa breve síntese das noções de eficiência presentes nos fluxos de comércio internacional, o trabalho empírico do artigo buscou caracterizar a composição das exportaçôes dos países do BRIC a partir das variáveis taxa de crescimento de suas exportações e importações, composição relativa da pauta de comércio e evolução do saldo comercial, as quais foram organizadas de acordo com classificação internacional presente em Lall (2000).

$\mathrm{Na}$ sequência, tais variáveis foram classificadas em cinco grupos setoriais (produtos primários, manufaturas baseadas em recursos, manufaturas de baixa intensidade tecnológica, manufaturas de média intensidade tecnológica e manufaturas de alta intensidade tecnológica), permitindo associar o padrão de comércio dos países do BRIC com os três tipos de eficiência apontados, em que quanto maiores forem as taxas de crescimento das exportaçôes, os saldos comerciais e a composição da pauta comercial em produtos primários e em manufaturas baseadas em recursos, mais próximo o país estará da eficiência ricardiana. Por outro lado, se os resultados das taxas de crescimento das exportações, dos saldos comerciais e da composição da pauta comercial estiverem concentrados nos produtos de maior intensidade tecnológica, os país tenderá às eficiências em crescimento e schumpeteriana.

Também foram calculados três indicadores de comércio exterior, descritos seguir, em termos setoriais desagregados de acordo com a classificação internacional de Lall (2000). As informações estatísticas foram extraídas da base de dados Comtrade/ Unctad, para o período 2000-2012 e para os subperíodos 2000-2002 e 2010-2012. A classificação utilizada agrega os produtos a partir do sistema internacional SITC - Revisão 2 e desagregação a três dígitos. 


\subsection{Market-share (MS)}

O MS refere-se à parcela de mercado obtida pelo país, calculada em relação ao total exportado mundialmente. Sua fórmula é:

$$
\begin{array}{r}
M S=\frac{X_{i K}}{X_{K}} ; X_{i K}=\text { exportação do produto } \mathrm{K} \text { no país i } \\
X_{K}=\text { exportações mundiais do produto } \mathrm{K}
\end{array}
$$

\subsection{Vantagens comparativas reveladas (VCR)}

Também será calculado o índice VCR, que incorpora a participação de um país no total das exportações mundiais, indicando se o país possui ou não vantagem comparativa nas exportaçōes de determinado produto. Sua fórmula é:

$$
\begin{aligned}
& V C R=\frac{X_{i K} / X_{i}}{X_{K} / \mathrm{X}} ; \quad X_{i K}=\text { exportação do produto } \mathrm{K} \text { pelo país i } \\
& X_{i}=\text { exportações totais do país } \mathrm{i} \\
& X_{K}=\text { exportação mundial do produto } \mathrm{k} \\
& X=\text { exportações mundiais totais }
\end{aligned}
$$

O índice VCR é, portanto, a razão entre a proporção de determinado produto na pauta de exportação do país em relação à proporção do mesmo produto na pauta de exportação mundial. Assim, quando a proporção das exportações desse produto no país é maior do que a proporção das exportaçôes desse país no mundo, VCR $>1$, ou ainda se a participação desse produto nas exportações totais de todos os produtos desse país for superior à mesma participação referente à economia mundial, diz-se que o país apresenta vantagem comparativa revelada nesse produto.

Entretanto, este índice apresenta um viés de assimetria, podendo variar de 0 a $\infty$, conferindo um peso maior para os valores acima de 1 do que para aqueles abaixo de 1, que ficam comprimidos entre 0 e 1 . Para tornar o índice de VCR simétrico, o presente estudo realizou o seguinte procedimento: (VCR - 1) / (VCR $+1)$. Assim, os resultados de VCR estarão entre -1 e +1 , sendo que os valores entre 0 e +1 representam vantagens comparativas e entre 0 e -1 significam desvantagens comparativas. 


\section{3. Índice de contribuição ao saldo comercial (ICSC)}

Devido à necessidade de uma medida de especialização que incorpore tanto as exportaçōes quanto as importações, para se tentar evitar uma visão unilateral da especialização comercial dos países, foi calculado o ICSC da seguinte maneira:

$$
C S=S_{1}-S_{2}
$$

Sendo: $S_{1}=100 \times \frac{\left(X_{i}-M_{i}\right)}{\left[\frac{\left(X_{j}+M_{j}\right)}{2}\right]}$ e $S_{2}=\frac{100 \times\left(X_{j}-M_{j}\right)}{\frac{\left(X_{j}+M_{j}\right)}{2} \times \frac{\left(X_{i}+M_{i}\right)}{\left(X_{j}+M_{j}\right)}}$

Onde $X_{i}$ e $M_{i}$ são as exportações e importações do produto $i$ efetuadas pelo país $j$. E $X_{j}$ e $M_{j}$ são as exportações e importações totais do país $j$.

Estes três indicadores de comércio internacional foram associados com os grupos setoriais, de acordo com a intensidade tecnológica, da seguinte forma: quanto maior o MS e quanto mais valores positivos do VCR e do ICSC estiverem relacionados aos produtos primários e às manufaturas baseadas em recursos, mais o país se aproximará da eficiência ricardiana, e quando estes valores estiverem associados aos grupos setoriais de maior intensidade tecnológica, maior é a convergência do país com as eficiências em crescimento e schumpeteriana.

\section{Estrutura e evolução do padrão de especialização dos países do BRIC no período 2000-2012}

A evolução dos fluxos de comércio internacional, até 2008, foi fortemente favorável aos países integrantes do BRIC, que se aproveitaram deste cenário mundial próspero, com crescimento da demanda externa e dos investimentos. Entretanto, a crise de 2008 trouxe consequências à continuidade deste ciclo virtuoso. De acordo com Libânio (2012), a crise financeira das hipotecas nos EUA refletiu sobre a economia real de diversos países e a economia mundial entrou em um período de baixas taxas de crescimento. Como consequência, o comércio internacional declinou fortemente, primeiro nos EUA e em alguns países desenvolvidos e depois nos países em desenvolvimento. Mesmo assim, uma parcela destes últimos continuou a se destacar como economias emergentes, com elevadas taxas de participação no comércio internacional e com grande potencial de crescimento. 
Os produtos de elevado conteúdo tecnológico continuaram apresentando alto dinamismo no comércio internacional, com redução do tempo de criação e inovação, resultando em constante reciclagem de tecnologias já existentes. Ademais, os produtos baseados em recursos naturais passaram por um período de grande demanda internacional e alta dos preços, influenciados principalmente pelo crescimento acelerado de economias, como as da China e Índia.

A pressuposição adotada aqui é que o cenário internacional, a inserção externa e as políticas implementadas geram efeitos sobre a trajetória dos países no comércio mundial. Por isso, é insuficiente a constatação de que as economias do BRIC estão passando por um período de crescimento excepcional, devendo-se somar a este aspecto a caracterização do padrão de especialização, que produzirá efeitos sobre o crescimento de longo prazo.

Nesse sentido, a presente seção investiga qual o padrão de especialização dos BRICs. Em outros termos, procura-se verificar se seus respectivos perfis de comércio sofreram alteraçôes substantivas nos anos 2000 e, em caso positivo, qual a natureza e qualidade destas modificações.

\subsection{Composição relativa e saldo comercial dos fluxos de comércio dos países do BRIC}

Nesta seção, busca-se caracterizar a evolução dos fluxos de comércio exterior do BRIC no período recente, com base na análise da taxa de crescimento das exportações e importações, da composição relativa da pauta de comércio e da evolução do saldo comercial.

A fim de qualificar as diversas trajetórias de crescimento dos países do BRIC, a Tabela 1 apresenta a taxa de crescimento média anual das exportaçôes e importações, por intensidade tecnológica no período 2000-2012. Observa-se que as economias do BRIC experimentaram forte impulso, tanto das exportações quanto das importações, gerando reflexos nas taxas de crescimento, que ficaram muito acima das taxas mundiais em todos os grupos setoriais.

Entretanto, um fato a ser destacado é que o incremento das importações em alguns casos foi maior do que o das exportações. Nesse sentido, o Brasil e a Rússia apresentaram semelhanças, pois obtiveram incremento maior nas importações em baixa, média e alta Intensidade Tecnológica. Em contrapartida, o ritmo de crescimento das exportaçôes foi maior do que o das importaçôes em produtos primários e manufaturas baseadas em recursos. Dependendo do grau de concentração nestes 
grupos, tal evolução pode sinalizar certa dependência da importação de setores com maior valor agregado, em detrimento de uma especialização em grupos de menor valor agregado. Em sentido oposto, a Índia e a China ampliaram mais as importações em produtos primários, em consequência do crescimento interno dessas economias e, por outro lado, obtiveram melhores taxas de crescimento relativo das exportações em média e alta intensidade tecnológica, e a China também em baixa intensidade tecnológica.

TABELA 1

Taxas anuais de crescimento das exportaçôes e importações, segundo intensidade tecnológica Mundo e países do BRIC - 2000-2012

\begin{tabular}{|c|c|c|c|c|c|}
\hline \multirow{2}{*}{ Setores/Exportação e importação } & & & & \multicolumn{2}{|c|}{ Em porcentagen } \\
\hline & Mundo & Brasil & Rússia & Índia & China \\
\hline \multicolumn{6}{|l|}{ Produtos primários } \\
\hline Exportações & 12,4 & 17,9 & 20,7 & 16,1 & 12,7 \\
\hline Importaçōes & 14,3 & 14,7 & 14,9 & 24,9 & 31,0 \\
\hline \multicolumn{6}{|l|}{ Manufaturas baseadas em recursos } \\
\hline Exportaçōes & 11,6 & 15,6 & 23,0 & 21,4 & 20,5 \\
\hline Importaçōes & 11,3 & 15,0 & 16,0 & 14,8 & 24,2 \\
\hline \multicolumn{6}{|c|}{ Manufaturas de baixa intensidade tecnológica } \\
\hline Exportações & 7,7 & 6,9 & 9,6 & 13,0 & 17,5 \\
\hline Importaçōes & 6,9 & 16,9 & 27,3 & 21,6 & 11,2 \\
\hline \multicolumn{6}{|c|}{ Manufaturas de média intensidade tecnológica } \\
\hline Exportaçōes & 8,5 & 13,4 & 15,0 & 24,0 & 23,5 \\
\hline Importaçōes & 8,1 & 14,4 & 25,2 & 21,4 & 17,0 \\
\hline \multicolumn{6}{|c|}{ Manufaturas de alta intensidade tecnológica } \\
\hline Exportações & & 10,5 & 10,7 & 22,0 & 25,4 \\
\hline Importações & 8,2 & 12,6 & 25,8 & 21,1 & 21,3 \\
\hline
\end{tabular}

Fonte: Comtrade (2013). Elaboração dos autores.

A Tabela 1 traz uma primeira evidência de eficiência ricardiana para o Brasil e a Rússia, com taxas maiores de crescimento das exportaçōes nos grupos em que ambos os países detêm abundância de recursos naturais. Já a Índia e principalmente a China, apresentam indícios de eficiência em crescimento, com taxas elevadas de exportação em grupos de maior elasticidade-renda, e também de eficiência schumpeteriana, pois os setores de maior intensidade tecnológica apresentam maior cumulatividade tecnológica. 
Tomando-se como referência estas taxas de crescimento das exportações e importaçōes, foi possível verificar o potencial de crescimento dos diferentes grupos setoriais no período e seu dinamismo com relação ao mercado internacional. $\mathrm{O}$ próximo passo é avaliar se essas exportaçôes cresceram em ritmo satisfatório. ${ }^{1}$

O Gráfico 1 demonstra que todos os países do BRIC tiveram mais "perda" de dinamismo de seus produtos do que "ganho". A China e a Índia foram as economias que registraram melhor desempenho, com "ganho" de, respectivamente, 42\% e 45\% dos produtos exportados. Em contrapartida, o Brasil e a Rússia apresentaram "ganho" em apenas $30 \%$ e $26 \%$ destes produtos. Tal fato evidencia uma concentração e especialização destes países em um número menor de produtos, dado que muitos deles tiveram perda de participação relativa.

\section{GRÁFICO 1}

"Ganho" e "Perda" de dinamismo em crescimento por produto Países do BRIC - 2000-2002/2010-2012

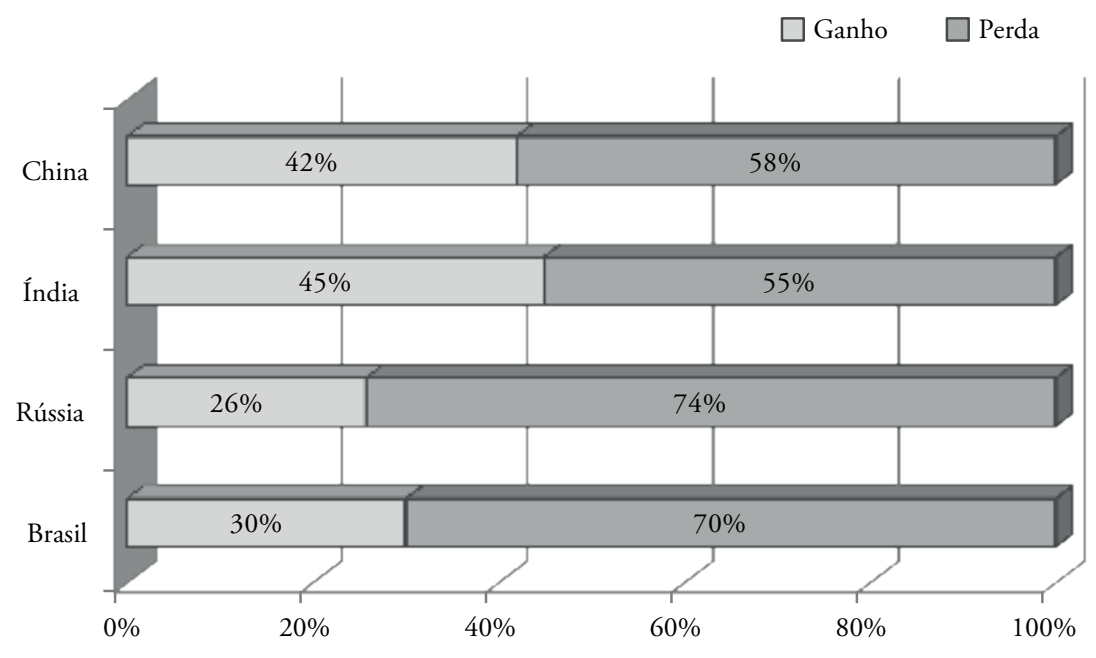

Fonte: Comtrade (2013). Elaboração dos autores.

1 Para essa avaliação assume-se, como em Martins (2004), que o ritmo de crescimento satisfatório do produto "X" é atingido se ele for capaz de garantir a participação que tinha nas exportaçōes totais do país "J" no início de determinado período. A "exportação potencial" será o valor das exportaçóes do produto "X" no período 2010-2012 compatível com a manutenção da taxa de participação relativa de 2000-2002. Dessa forma, consideram-se "ganho" de dinamismo em crescimento, relativamente ao valor da "exportação potencial", os produtos cuja participação relativa nas exportaçôes em 2010-2012 é maior do que em 2000-2002, e "perda" aqueles com participação menor. Esse cálculo foi feito para 233 produtos para cada um dos países do BRIC, a partir de dados do Comtrade (2013), revisão 2 desagregados a 3 dígitos. 
A compreensão da qualidade em que estes "ganhos" se efetivaram e o reflexo destes movimentos sobre a participação na pauta exportadora dos países do BRIC podem ser visualizados na Tabela 2, que divide os produtos em grupos setoriais para 2000-2002 e 2010-2012.

TABELA 2

Pauta comercial exportadora, segundo intensidade tecnológica

Países do BRIC - 2000-2012

\begin{tabular}{l|r|r|r|r|r|r|rr}
\hline \multirow{3}{*}{ Setores } & \multicolumn{2}{c|}{ Brasil } & \multicolumn{2}{c}{ Rússia } & \multicolumn{2}{c}{ Índia } & \multicolumn{2}{c}{ China } \\
\cline { 2 - 10 } & $\mathbf{2 0 0 0 -}$ & $\mathbf{2 0 1 0 -}$ & $\mathbf{2 0 0 0 -}$ & $\mathbf{2 0 1 0 -}$ & $\mathbf{2 0 0 0 -}$ & $\mathbf{2 0 1 0 -}$ & $\mathbf{2 0 0 0 -}$ & $\mathbf{2 0 1 0 -}$ \\
& $\mathbf{2 0 0 2}$ & $\mathbf{2 0 1 2}$ & $\mathbf{2 0 0 2}$ & $\mathbf{2 0 1 2}$ & $\mathbf{2 0 0 2}$ & $\mathbf{2 0 1 2}$ & $\mathbf{2 0 0 2}$ & $\mathbf{2 0 1 2}$ \\
\hline Produtos primários & 23,5 & 32,6 & 49,4 & 54,9 & 14,1 & 11,9 & 6,7 & 3,2 \\
Manuf. baseadas em recursos & 27,0 & 35,4 & 18,7 & 25,5 & 29,0 & 37,7 & 8,7 & 8,3 \\
Manuf. de baixa intens. tecn. & 11,4 & 5,3 & 4,3 & 1,9 & 36,5 & 21,6 & 39,5 & 30,4 \\
Manuf. de média intens. tecn. & 24,0 & 19,0 & 11,3 & 7,9 & 12,0 & 18,4 & 19,7 & 24,1 \\
Manuf. de alta intens. tecn. & 11,9 & 5,0 & 3,8 & 1,2 & 5,8 & 7,5 & 24,6 & 33,5 \\
\hline
\end{tabular}

Fonte: Comtrade (2013). Elaboração dos autores.

Como desdobramento da análise feita anteriormente, desagregada por produtos, a pauta comercial exportadora caminhou em direção à maior concentração em determinados grupos setoriais. O Brasil e a Rússia tiveram "ganho" de dinamismo em crescimento nos setores de produtos primários e manufaturas baseadas em recursos vis-à-vis a perda de participação nos grupos de baixa, média e alta intensidade tecnológica. Observa-se que, dos quatro países, a Rússia apresentou a maior concentração da pauta em produtos primários, com 54,9\% em 2010-2012, seguida pelo Brasil $(32,6 \%)$. Este movimento de maior concentração das pautas brasileira e russa em produtos primários e manufaturas baseadas em recursos é compatível com a eficiência ricardiana, caracterizada, em um de seus aspectos, com a neutralidade do que se produz e com a especialização das exportações.

A Índia e a China contabilizaram ganho de participação em média e alta intensidade tecnológica. Entretanto, a Índia concentrou a pauta exportadora em manufaturas baseadas em recursos e baixa intensidade tecnológica, enquanto a China apresentou nos últimos anos maior concentração em baixa e alta intensidade tecnológica. Destaque deve ser dado a este último país, que foi capaz de transformar a especialização em baixa intensidade tecnológica, no início dos anos 2000, para alta intensidade, no último 
triênio analisado. Essa mudança é característica da eficiência schumpeteriana, pois a China buscou uma inserção positiva em produtos com elevadas oportunidades de desenvolvimento tecnológico e de expansão do comércio no longo prazo.

Este resultado corrobora o êxito do processo de inserção externa da China, pautado no desenvolvimento industrial, no qual o país vem se especializando na exportação de produtos de maior valor agregado, enquanto os países ricos em recursos naturais ampliam a participação nestes segmentos, a fim de abastecer a demanda chinesa.

Segundo Negri e Passos (2009), os responsáveis pela ampliação da participação das commodities nas exportações brasileiras foram o aumento dos preços e a elevada demanda internacional, especialmente da China e da Índia, que, após a crise de 2008, tiveram crescimento da demanda por produtos do Brasil superior ao dos países desenvolvidos. Em 2009, a China já era o principal parceiro comercial do Brasil e $80 \%$ das exportaçóes para este país eram de commodities, concentradas principalmente em minério de ferro, soja em grão e petróleo bruto. Além disso, a volta da valorização do real em relação ao dólar contribuiu para a maior especialização da pauta exportadora do país nestes produtos de menor intensidade tecnológica.

Sobre este assunto, Almeida (2011) aponta que o crescimento dos produtos básicos nas exportações brasileiras relaciona-se ao fato de o país ter vantagens comparativas em sua produção e ao aumento de $276 \%$ do índice de preços das exportaçóes de produtos básicos, entre 2003 e 2011, enquanto a quantidade ampliou-se em 136\%, sendo, portanto, o efeito preço maior do que o efeito quantidade. Outro fator que exerceu influência no período foi a mudança de preço relativo. O preço das exportações de manufaturados cresceu em 99\%, de 2003 a 2011, muito abaixo do preço dos bens básicos. Dessa forma, independentemente do valor da taxa de câmbio, tornou-se muito mais rentável a exportação de commodities do que a de manufaturados.

Para Hiratuka e Cunha (2011), uma melhor inserção no comércio internacional não necessariamente deve ser obtida por meio da promoção de mudanças estruturais que reduzam o peso das commodities em relação aos produtos mais sofisticados e intensivos em capital e tecnologia. Os autores constatam que existe grande variedade de valores médios de qualidade dos produtos, apontando diferenças de qualidade, mesmo em produtos com elevado nível de desagregação. Assim, as políticas comercial, industrial e tecnológica devem estimular a especialização no interior de cada grupo de produtos e coordenar as decisões privadas para que avancem nas cadeias de valores dos vários setores industriais em busca de segmentos mais nobres. 
A Tabela 3 faz a mesma análise anterior para o caso das importaçóes. Observa-se que os ganhos de participação relativa para as importaçōes brasileiras e russas, no período de 2000-2002 a 2010-2012, concentraram-se em produtos de maior valor agregado, enquanto para a China e Índia a situação foi inversa, com ganhos de participação relativa em produtos primários.

De forma geral, a pauta comercial importadora para estes países foi menos concentrada do que a exportadora, sendo que o Brasil e a Rússia concentraram as importações em média intensidade tecnológica (respectivamente, 38\% e 35\% em 20102012), a Índia em produtos primários (37\%) e a China em alta intensidade tecnológica (28\%). De acordo com o Ipea (2011), esta concentração das importaçôes chinesas em produtos de maior intensidade tecnológica pode parecer paradoxal, dado que o país é também grande exportador deste setor. Entretanto, tal resultado é possível, pois a produção de produtos de alta intensidade tecnológica está internacionalmente integrada e depende da importação de componentes intensivos em tecnologia.

TABELA 3

Pauta comercial importadora, segundo intensidade tecnológica Países do BRIC - 2000-2012

Em porcentagem

\begin{tabular}{l|c|c|c|c|c|c|c|c}
\hline \multirow{2}{*}{ Setores } & \multicolumn{2}{|c|}{ Brasil } & \multicolumn{2}{c|}{ Rússia } & \multicolumn{2}{c|}{ Índia } & \multicolumn{2}{c}{ China } \\
\cline { 2 - 10 } & $\mathbf{2 0 0 0}-$ & $\mathbf{2 0 1 0}-$ & $\mathbf{2 0 0 0}-$ & $\mathbf{2 0 1 0}-$ & $\mathbf{2 0 0 0}-$ & $\mathbf{2 0 1 0}-$ & $\mathbf{2 0 0 0}-$ & $\mathbf{2 0 1 0 -}$ \\
& $\mathbf{2 0 0 2}$ & $\mathbf{2 0 1 2}$ & $\mathbf{2 0 0 2}$ & $\mathbf{2 0 1 2}$ & $\mathbf{2 0 0 2}$ & $\mathbf{2 0 1 2}$ & $\mathbf{2 0 0 2}$ & $\mathbf{2 0 1 2}$ \\
\hline Produtos primários & 16,1 & 15,9 & 16,3 & 10,0 & 34,9 & 36,9 & 12,7 & 21,8 \\
Manuf. baseadas em recursos & 18,0 & 18,2 & 18,4 & 11,6 & 26,7 & 18,8 & 13,3 & 19,2 \\
Manuf. de baixa intens. tecn. & 6,3 & 9,3 & 10,9 & 14,8 & 5,0 & 4,9 & 11,0 & 4,7 \\
Manuf. de média intens. tecn. & 35,0 & 38,0 & 29,5 & 35,0 & 14,1 & 16,5 & 31,6 & 23,3 \\
Manuf. de alta intens. tecn. & 24,0 & 19,0 & 13,8 & 16,6 & 9,7 & 9,0 & 30,4 & 28,0 \\
\hline
\end{tabular}

Fonte: Comtrade (2013). Elaboração dos autores.

Os resultados apresentados revelam que o Brasil e a Rússia, devido à disponibilidade de recursos naturais e ao cenário internacional favorável no período, ampliaram as exportações de produtos intensivos em recursos naturais. Tal fato, por si só, não representa um fator negativo, uma vez que estes países tiveram, no período, elevados ganhos econômicos a partir destes produtos. O problema que pode surgir de tal cenário é que a natureza destes produtos pode estar relacionada com ganhos de curto prazo, e daí a necessidade de o país, além de buscar ganhos nestes setores, perseguir o progresso nos grupos setoriais mais dinâmicos, como apontado pela análise baseada na eficiência schumpeteriana. 
Uma evidência da Tabela 1 apontou nesta direção, ao revelar uma taxa de crescimento média anual das exportaçōes de alta intensidade tecnológica, para o Brasil e a Rússia, em torno de $10 \%$ no período de 2000 a 2012. Entretanto, constataram-se também taxas elevadas de importação nestes setores, juntamente com a perda de participação relativa na pauta exportadora. O resultado final destes movimentos pode ser captado pelo saldo comercial, que fornecerá os valores absolutos de exportações e importaçôes, revelando assim os esforços que cada país empreendeu nestes anos para atingir ou não superávits comerciais.

A Tabela 4 apresenta a média anual do saldo comercial por intensidade tecnológica para os países do BRIC. No saldo comercial total, ocorreu uma explosiva acumulação dos superávits destes países, com exceção da Índia, que obteve déficits nos dois períodos (2000-2002 e 2010-2012).

Porém, a análise feita por intensidade tecnológica não deixa dúvida quanto à divergência existente tanto no nível setorial, dentro de um mesmo país, quanto entre os componentes do BRIC. De um lado, têm-se Brasil, Rússia e Índia, que acumularam déficits crescentes nos grupos setoriais de média e alta intensidade tecnológica, e, de outro lado, está a China, que foi capaz de modificar o saldo comercial de déficits, no início dos anos 2000, para superávits significativos em 2010-2012 nestes mesmos grupos.

TABELA 4

Média anual do saldo comercial, segundo intensidade tecnológica Países do BRIC - 2000-2012

\begin{tabular}{l|c|c|c|c|c|c|c|c}
\hline \multirow{4}{*}{ Setores } & \multicolumn{2}{c}{ Brasil } & \multicolumn{2}{c}{ Rússia } & \multicolumn{2}{c}{ Índia } & \multicolumn{2}{c}{ China } \\
\cline { 2 - 10 } & $\mathbf{2 0 0 0 -}$ & $\mathbf{2 0 1 0}-$ & $\mathbf{2 0 0 0}-$ & $\mathbf{2 0 1 0}-$ & $\mathbf{2 0 0 0}-$ & $\mathbf{2 0 1 0}-$ & $\mathbf{2 0 0 0}-$ & $\mathbf{2 0 1 0 -}$ \\
$\mathbf{2 0 0 2}$ & $\mathbf{2 0 1 2}$ & $\mathbf{2 0 0 2}$ & $\mathbf{2 0 1 2}$ & $\mathbf{2 0 0 2}$ & $\mathbf{2 0 1 2}$ & $\mathbf{2 0 0 2}$ & $\mathbf{2 0 1 2}$ \\
\hline Produtos primários & 5 & 42 & 44 & 234 & -12 & -128 & -14 & -301 \\
Manuf. baseadas em recursos & 6 & 44 & 12 & 86 & -1 & 20 & -10 & -164 \\
Manuf. de baixa intens. tecn. & 3 & -7 & 0 & -33 & 14 & 37 & 83 & 483 \\
Manuf. de média intens. tecn. & -5 & -35 & 0 & -61 & -2 & -22 & -25 & 59 \\
Manuf. de alta intens. tecn. & -6 & -28 & -2 & -41 & -3 & -19 & -8 & 154 \\
Total & $\mathbf{5}$ & $\mathbf{2 2}$ & $\mathbf{6 3}$ & $\mathbf{1 9 6}$ & $\mathbf{- 8}$ & $-\mathbf{1 6 3}$ & $\mathbf{2 6}$ & $\mathbf{1 8 9}$ \\
\hline
\end{tabular}

Fonte: Comtrade (2013). Elaboração dos autores. 
Apesar dos déficits acumulados nos setores citados, para o Brasil e a Rússia, o resultado total do saldo comercial foi positivo devido aos elevadíssimos superávits dos grupos de produtos primários e manufaturas baseadas em recursos. Este resultado positivo esteve relacionado ao ciclo de valorização das commodities, o que, para Negri e Alvarenga (2011), pode perdurar por um período relativamente longo em função do desequilíbrio entre oferta e demanda de alimentos, do crescimento do custo de energia, da ampliação da produção de biocombustíveis nos EUA e na Europa, do enfraquecimento do dólar e do crescimento chinês. Assim, neste cenário não se pode desconsiderar a importância do bom desempenho desse setor para a economia brasileira e a oportunidade que ele representa para a geração de superávits. Todavia, é necessário observar seus possíveis efeitos no longo prazo sobre a estrutura produtiva.

A configuração do saldo comercial para os quatro países do BRIC confirma um padrão de especialização do Brasil e da Rússia baseado na eficiência ricardiana, ao obterem saldos positivos em produtos com vantagem comparativa de custos. A China apresenta tanto um padrão baseado na eficiência em crescimento, na qual os produtos diferenciam-se entre si e a estrutura produtiva é importante, ao buscar transformar seu quadro de déficits em superávits nos setores de maior intensidade tecnológica, quanto uma eficiência schumpeteriana, ao participar de grupos setoriais mais dinâmicos no mercado internacional. Já a Índia configura-se como um país com inserção comercial indefinida, porém, aproximando-se de melhores posições em setores de baixa intensidade tecnológica.

A conclusão deste item é que o padrão de comércio dos países do BRIC se caracterizou, no período de 2000-2002 a 2010-2012, por uma maior concentração em determinados grupos setoriais, sendo que o Brasil e a Rússia concentraram-se nos setores de menor dinamismo no comércio internacional, enquanto a Índia e em especial a China tiveram maior participação em setores mais dinâmicos. Para os casos brasileiro e russo, o relativo maior grau de sofisticação da pauta importadora e a elevada concentração das exportações nos grupos setoriais de menor valor agregado indicam a baixa qualidade do padrão de especialização destes países, diferentemente da Índia e, principalmente, da China, que apresentaram elevação significativa no período da qualidade do padrão de especialização. Não obstante, os resultados do saldo comercial revelam que o Brasil e a Rússia não se aproveitaram deste momento de boom dos superávits dos setores baseados em recursos naturais para melhorar suas posiçôes em grupos setoriais mais dinâmicos. 


\subsection{Indicadores de comércio internacional para os países do BRIC no período recente}

Após a análise das taxas de crescimento, da composição relativa dos fluxos de comércio e do saldo comercial dos países do BRIC, esta seção apresenta alguns indicadores selecionados de comércio exterior, a fim de captar a ocorrência de mudanças estruturais no padrão de comércio de cada país.

\subsubsection{Market-share (MS) dos países do BRIC no período recente}

O primeiro indicador de comércio exterior a ser analisado é o MS, que expressa a proporção das exportações de determinado produto ou grupo setorial relativamente às exportações mundiais deste mesmo produto ou grupo setorial. A partir dele será possível analisar o desempenho de cada país em relação ao mundo nos triênios 2000-2002 e 2010-2012.

TABELA 5

Market share, segundo intensidade tecnológica (1)

Países do BRIC - 2000-2012

\begin{tabular}{l|c|c|c|c|c|c|c|c}
\hline \multirow{4}{*}{ Setores } & \multicolumn{2}{c|}{ Brasil } & \multicolumn{2}{c}{ Rússia } & \multicolumn{2}{c}{ Índia } & \multicolumn{2}{c}{ China } \\
\cline { 2 - 10 } & $\mathbf{2 0 0 0 -}$ & $\mathbf{2 0 1 0}$ & $\mathbf{2 0 0 0}-$ & $\mathbf{2 0 1 0}$ & $\mathbf{2 0 0 0}-$ & $\mathbf{2 0 1 0}$ & $\mathbf{2 0 0 0}$ & $\mathbf{2 0 1 0}$ \\
$\mathbf{2 0 0 2}$ & $\mathbf{2 0 1 2}$ & $\mathbf{2 0 0 2}$ & $\mathbf{2 0 1 2}$ & $\mathbf{2 0 0 2}$ & $\mathbf{2 0 1 2}$ & $\mathbf{2 0 0 2}$ & $\mathbf{2 0 1 2}$ \\
\hline Produtos primários & 1,67 & 2,92 & 6,26 & 10,17 & 0,78 & 1,24 & 2,32 & 2,30 \\
Manuf. baseadas em recursos & 1,86 & 2,93 & 2,29 & 4,36 & 1,57 & 3,65 & 2,89 & 5,47 \\
Manuf. de baixa intens. tecn. & 0,75 & 0,60 & 0,51 & 0,45 & 1,87 & 2,85 & 12,50 & 27,35 \\
Manuf. de média intens. tecn. & 0,74 & 1,22 & 0,63 & 1,04 & 0,29 & 1,37 & 2,98 & 12,21 \\
Manuf. de alta intens. tecn. & 0,50 & 0,47 & 0,29 & 0,25 & 0,20 & 0,87 & 5,14 & 26,39 \\
Total & $\mathbf{0 , 9 5}$ & $\mathbf{1 , 5 0}$ & $\mathbf{1 , 6 9}$ & $\mathbf{3 , 0 9}$ & $\mathbf{0 , 7 4}$ & $\mathbf{1 , 7 4}$ & $\mathbf{4 , 5 9}$ & $\mathbf{1 1 , 8 7}$ \\
\hline
\end{tabular}

Fonte: Comtrade (2013). Elaboração dos autores.

(1) De acordo com a classificação de Lall (2000).

Quanto à participação total do MS dos quatro países, observa-se que todos apresentaram valores crescentes, caracterizando o melhor desempenho destes no cenário internacional. No último triênio, o MS foi de 11,87\% para a China, 3,09\% para a Rússia, 1,74\% para a Índia e 1,50\% para o Brasil.

Entretanto, apesar dos valores crescentes em termos totais na participação do comércio internacional, quando realizada a desagregação por grupos setoriais, 
observa-se uma forte assimetria entre os setores. No mesmo sentido da análise feita no item anterior, os maiores valores do MS do Brasil e da Rússia concentraram-se nos produtos de menor intensidade tecnológica, não obstante a pequena participação em setores mais intensivos em tecnologia. Apesar disso, os dois países apresentaram crescimento do MS em três grupos setoriais (produtos primários, manufaturas baseadas em recursos naturais e manufaturas de média intensidade tecnológica) e decrescimento em dois grupos (manufaturas de baixa intensidade tecnológica e de alta intensidade tecnológica). A Índia concentrou-se em manufaturas baseadas em recursos e manufaturas de baixa intensidade tecnológica. A China exibiu os valores mais significativos em produtos mais intensivos em tecnologia, com MS de $26 \%$, no último triênio, em alta intensidade tecnológica. Por fim, a China e a Índia, além de terem participação em setores mais intensivos em tecnologia, contabilizaram valores crescentes em todos os grupos setoriais, com exceção da China em produtos primários (Tabela 5).

Essa composição do MS confirma um padrão de eficiência em crescimento para a China e a ausência deste padrão para o Brasil e a Rússia. Tal tipo de eficiência é caracterizada pela substituição da produção de bens primários por bens industrializados, o que promove ganhos de produtividade e maior nível de encadeamento dentro da economia, gerando mais crescimento, produção e emprego.

Apesar da pequena participação do Brasil em alta intensidade tecnológica no comércio internacional, Negri (2009) aponta que, para atuar em inovação e aumentar as exportações em tais setores, o país dispõe de instrumentos legais para fomento de P\&D, como a PITCE (2003), a Lei do Bem (2005) e a Lei da Inovação (2004). Além disso, existem as instituições de fomento ao investimento e à $\mathrm{P} \& \mathrm{D}$, como o BNDES e a Finep. Entretanto, mesmo com esses esforços, ainda não se observou melhora nos indicadores de inovação. Cavalcante (2011), ao analisar tal fenômeno, sugere ser necessária a modernização da estrutura institucional responsável pelas políticas de CT\&I, a fim de que se tenha uma visão sistêmica do processo de inovação.

\subsubsection{Vantagens comparativas reveladas (VCR) dos países do BRIC no período recente}

O indicador de VCR é uma medida do desempenho exportador de um produto ou grupo setorial na pauta de um país relativamente ao seu desempenho na pauta mundial. Quando este valor for positivo, significa que o país apresentou vantagem 
comparativa em determinado produto e quando for negativo indica desvantagem comparativa.

Ao analisar o número de produtos com indicador VCR positivo para os países do BRIC (de um total de 237 produtos) no período 2010-2012 em relação ao triênio 2000-2002 (Tabela 6), o movimento característico para todos estes países foi de redução do número de produtos com VCR positivo, sendo muito mais representativa para o Brasil e a Rússia. Por outro lado, mesmo com a diminuição de produtos com vantagens comparativas, a participação relativa destes produtos na pauta exportadora aumentou para todos os países do BRIC Ou seja, estes países passaram por uma maior especialização de seus padrôes de comércio no início do século XXI.

TABELA 6

Número de produtos com indicador de VCR positivo e participação relativa na pauta exportadora Países do BRIC - 2010-2012

\begin{tabular}{l|cc|c|c|c|c}
\hline \multirow{2}{*}{ Países } & \multicolumn{2}{|c|}{$\mathbf{2 0 0 0 - 2 0 0 2}$} & \multicolumn{2}{c|}{$\mathbf{2 0 1 0 - 2 0 1 2}$} & \multicolumn{2}{c}{ Média 2000-2012 } \\
\cline { 2 - 7 } & $\begin{array}{c}\mathbf{N}^{\circ} \text { de } \\
\text { produtos }\end{array}$ & $\begin{array}{c}\text { \% da pauta } \\
\text { exportadora }\end{array}$ & $\begin{array}{c}\mathbf{N}^{\circ} \text { de } \\
\text { produtos }\end{array}$ & $\begin{array}{c}\text { \% da pauta } \\
\text { exportadora }\end{array}$ & $\begin{array}{c}\mathbf{N}^{\circ} \text { de } \\
\text { produtos }\end{array}$ & $\begin{array}{c}\text { \% da pauta } \\
\text { exportadora }\end{array}$ \\
\hline Brasil & 75 & 71,0 & 57 & 74,0 & 65 & 68,0 \\
Rússia & 41 & 85,0 & 31 & 90,0 & 30 & 88,0 \\
Índia & 80 & 81,0 & 77 & 73,0 & 83 & 76,0 \\
China & 94 & 79,0 & 92 & 83,0 & 91 & 81,0 \\
\hline
\end{tabular}

Fonte: Comtrade (2013). Elaboração dos autores.

Diante disso, a pergunta que se faz necessária é: qual a qualidade dos produtos com vantagens e desvantagens comparativas? Para responder a tal questão, a Tabela 7 traz o VCR por grupos setoriais.

A aplicação deste indicador às exportaçōes segundo intensidade tecnológica evidenciou a baixa qualidade estrutural do padrão de especialização do Brasil e da Rússia, a qualidade intermediária da Índia e a elevada qualidade estrutural do $p a-$ drão de especialização da China. Além disso, observou-se a manutenção no período estudado destas características para o Brasil e a Rússia, ou seja, nestes anos os dois países obtiveram um padrão de especialização estático ou pouco dinâmico, mantendo os valores positivos e negativos do indicador de VCR nos mesmos grupos setoriais: positivos em produtos primários e manufaturas baseadas em recursos e negativos 
nos demais. Não obstante, os maiores valores negativos foram para manufaturas de alta intensidade tecnológica, com valores crescentemente negativos no período. Por outro lado, a China apresentou mudanças favoráveis, sendo que no início dos anos 2000 registrava VCR positivo em dois grupos setoriais (manufaturas de baixa e de média intensidade tecnológica) e, período 2010-201,2 obteve VCR positivo em três grupos setoriais (baixa, média e alta intensidade tecnológica) (Tabela 7).

TABELA 7

Indicador de VCR, segundo intensidade tecnológica (1)

Países do BRIC - 2000-2012

\begin{tabular}{l|c|c|c|c|c|c|c|c}
\hline \multirow{4}{*}{ Setores } & \multicolumn{2}{c|}{ Brasil } & \multicolumn{2}{c|}{ Rússia } & \multicolumn{2}{c|}{ Índia } & \multicolumn{2}{c}{ China } \\
\cline { 2 - 10 } & $\mathbf{2 0 0 0 -}$ & $\mathbf{2 0 1 0 -}$ & $\mathbf{2 0 0 0 -}$ & $\mathbf{2 0 1 0 -}$ & $\mathbf{2 0 0 0 -}$ & $\mathbf{2 0 1 0 -}$ & $\mathbf{2 0 0 0 -}$ & $\mathbf{2 0 1 0 -}$ \\
& $\mathbf{2 0 0 2}$ & $\mathbf{2 0 1 2}$ & $\mathbf{2 0 0 2}$ & $\mathbf{2 0 1 2}$ & $\mathbf{2 0 0 2}$ & $\mathbf{2 0 1 2}$ & $\mathbf{2 0 0 2}$ & $\mathbf{2 0 1 2}$ \\
\hline Produtos primários & 0,27 & 0,40 & 0,57 & 0,59 & 0,02 & $-0,08$ & $-0,33$ & $-0,62$ \\
Manuf. baseadas em recursos & 0,31 & 0,42 & 0,13 & 0,27 & 0,34 & 0,45 & $-0,24$ & $-0,27$ \\
Manuf. de baixa intens. tecn. & $-0,13$ & $-0,31$ & $-0,55$ & $-0,70$ & 0,42 & 0,36 & 0,45 & 0,50 \\
Manuf. de média intens. tecn. & $-0,12$ & $-0,10$ & $-0,46$ & $-0,50$ & $-0,43$ & $-0,12$ & $-0,21$ & 0,01 \\
Manuf. de alta intens. tecn. & $-0,31$ & $-0,52$ & $-0,70$ & $-0,85$ & $-0,58$ & $-0,33$ & 0,06 & 0,38 \\
\hline
\end{tabular}

Fonte: Comtrade (2013). Elaboração dos autores.

(1) De acordo com a classificação de Lall (2000).

A partir destes indicadores, nota-se que a China parece mais uma vez ter se aproveitado da eficiência schumpeteriana, pois, ao passar de dois grupos com VCR positivo para três grupos com elevada intensidade tecnológica, apropriou-se de novos mercados, constatando que os produtos têm diferentes níveis de capacidade de inovação e distintas trajetórias tecnológicas.

Em resumo, no período estudado, as estruturas de VCR positivas e negativas foram de baixa qualidade e rígidas para o Brasil e a Rússia, sendo que a China foi a única economia, entre as quatro analisadas, que mostrou modificações em direção à melhor qualidade estrutural de suas vantagens. A Índia apresentou-se como um caso intermediário.

\subsection{3. Índice de contribuição ao saldo comercial (ICSC) dos países do BRIC no período recente}

Um indicador de especialização comercial mais completo, que incorpora as importações, é o ICSC. A partir dele, trona-se possível avaliar se um melhor desempenho 
nas exportações de determinado produto ou grupo setorial também resultou em elevação relativa das importações.

A Tabela 8 apresenta a média da porcentagem de produtos com desagregação a três dígitos (de um total de 234 produtos) que apresentaram valores positivos no ICSC, nos triênios 2000-2002 e 2010-2012 e em todo o período 2000-2012. Observa-se que o Brasil e a Rússia registraram valores abaixo dos 50\%, apresentando ainda queda entre 2000-2002 e 2010-2012 de 41\% para 32\% dos produtos, para o Brasil, e de $23 \%$ para $20 \%$, para a Rússia. Por outro lado, a Índia e a China revelaram ICSC positivo para mais da metade dos produtos exportados, sendo este valor crescente do primeiro triênio ao último, de 56\% para 59\% para a Índia e de $50 \%$ para $58 \%$ para a China.

TABELA 8

Porcentagem de produtos com ICSC positivo (1)

Países do BRIC - 2000-2012

\begin{tabular}{lcccc}
\hline Países & $\mathbf{2 0 0 0 - 2 0 0 2}$ & $\mathbf{2 0 1 0 - 2 0 1 2}$ & $\mathbf{2 0 0 0 - 2 0 1 2}$ \\
\hline Brasil & 41,0 & 32,0 & 39,0 \\
Rússia & 23,0 & 20,0 & 40,0 \\
Índia & 56,0 & 59,0 & 74,0 \\
China & 50,0 & 58,0 & 71,0 \\
\hline
\end{tabular}

Fonte: Comtrade (2013). Elaboração dos autores.

(1) De um total de 234 produtos.

Os resultados encontrados demonstram que o padrão de comércio do Brasil e da Rússia mostrou-se mais propenso à geração de déficits do que de superávits comerciais relativos, inversamente aos casos da Índia e da China.

Com o intuito de verificar o tipo e a origem destes produtos que contribuíram positivamente e negativamente para o saldo comercial, a Tabela 9 traz a agregação por intensidade tecnológica. Na mesma direção que o indicador de VCR, o Brasil e a Rússia ganham destaque nos primeiros grupos setoriais da classificação, com ICSC positivos e crescentes, mas registram ICSC negativos e crescentes nos últimos grupos setoriais. Ademais, o Brasil perdeu eficácia neste indicador, passando de três grupos com ICSC positivo, em 2000-2002, para dois grupos, em 2010-2012. A Índia apresentou situação intermediária, aumentando de dois para três grupos com ICSC positivo, entre os dois triênios, e a China realizou uma transformação considerável deste indicador, ampliando de apenas um para três setores com ICSC positivo, entre eles, baixa, média e alta intensidade tecnológica. 
TABELA 9

Índice de contribuição ao saldo comercial, segundo intensidade tecnológica Países do BRIC - 2000-2012

\begin{tabular}{l|c|c|c|c|c|c|c|c}
\hline \multirow{2}{*}{ Setores } & \multicolumn{2}{c|}{ Brasil } & \multicolumn{2}{c|}{ Rússia } & \multicolumn{2}{c|}{ Índia } & \multicolumn{2}{c}{ China } \\
\cline { 2 - 10 } & $\begin{array}{l}\mathbf{2 0 0 0 -} \\
\mathbf{2 0 0 2}\end{array}$ & $\begin{array}{c}\mathbf{2 0 1 0 -} \\
\mathbf{2 0 1 2}\end{array}$ & $\begin{array}{c}\mathbf{2 0 0 0 -} \\
\mathbf{2 0 0 2}\end{array}$ & $\begin{array}{c}\mathbf{2 0 1 0 -} \\
\mathbf{2 0 1 2}\end{array}$ & $\begin{array}{c}\mathbf{2 0 0 0 -} \\
\mathbf{2 0 0 2}\end{array}$ & $\begin{array}{c}\mathbf{2 0 1 0 -} \\
\mathbf{2 0 1 2}\end{array}$ & $\begin{array}{c}\mathbf{2 0 0 0 -} \\
\mathbf{2 0 0 2}\end{array}$ & $\begin{array}{c}\mathbf{2 0 1 0 -} \\
\mathbf{2 0 1 2}\end{array}$ \\
\hline Produtos Primários & 7,4 & 16,7 & 26,8 & 41,7 & $-20,7$ & $-23,6$ & $-6,0$ & $-18,5$ \\
Manuf. Baseadas em Recursos & 8,9 & 17,1 & 0,3 & 12,4 & 2,3 & 17,9 & $-4,6$ & $-10,9$ \\
Manuf. de Baixa Intens. Tecn. & 5,1 & $-3,9$ & $-5,4$ & $-12,2$ & 31,3 & 15,8 & 28,5 & 25,7 \\
Manuf. de Média Intens. Tecn. & $-11,0$ & $-18,4$ & $-14,8$ & $-25,3$ & $-2,0$ & 1,7 & $-11,8$ & 0,8 \\
Manuf. de Alta Intens. Tecn. & $-12,6$ & $-14,0$ & $-8,1$ & $-14,3$ & $-3,9$ & $-1,4$ & $-5,7$ & 5,5 \\
\hline
\end{tabular}

Fonte: Comtrade (2013). Elaboração dos autores.

Em linhas gerais, o indicador de ICSC aponta para a existência de uma rigidez da estrutura de contribuição ao saldo comercial do Brasil e da Rússia, pois os ICSC positivos e negativos mantiveram-se basicamente inalterados ao longo do período analisado. Além disso, tais estruturas rígidas se aprofundaram no período, com as possibilidades de ampliação do superávit comercial cada vez mais dependente do desempenho das exportaçôes dos produtos de baixo valor agregado, ao passo que os produtos de maior valor agregado tiveram posição crescentemente deficitária, ampliando a pressão negativa sobre a balança comercial.

Os resultados finais deste indicador, mesmo acrescentando-se as importações, confirmam os resultados obtidos pelo VCR, evidenciando assim que o padrão de especialização, analisado pela estrutura das vantagens e desvantagens comparativas, prevaleceu inalterado para o Brasil e a Rússia e sofreu modificações positivas e significativas para a China, sendo a Índia ainda um caso intermediário.

Quanto ao tipo de eficiência no comércio, no mesmo sentido que o VCR, o ICSC confirma a eficiência ricardiana para o Brasil e a Rússia e as eficiências em crescimento e schumpeteriana para a Índia e, principalmente, para a China.

\section{Considerações finais}

O início do século XXI foi marcado pelo extraordinário aumento das exportações mundiais, com taxa média de crescimento de $10,5 \%$ ao ano entre 2001 e 2011. Diante deste desempenho e da perspectiva de acirramento da concorrência internacional, viu-se a necessidade de avaliar a evolução dos fluxos de comércio, neste período, para os países do BRIC. 
Para atender ao objetivo do artigo, foram analisados o crescimento, a composição relativa e o saldo comercial dos fluxos de comércio do BRIC, além dos cálculos envolvendo indicadores de comércio exterior, a fim de captar a especialização e a evolução comercial desses países, bem como a correlação com a eficiência ricardiana, a eficiência em crescimento e a eficiência schumpeteriana.

A análise da taxa de crescimento e da composição relativa dos fluxos de comércio e do saldo comercial do BRIC encontrou, para o Brasil e a Rússia, uma melhora no desempenho dessas variáveis para produtos de menor valor agregado e uma piora para produtos de maior intensidade tecnológica. Já para a Índia e, principalmente, a China, verificou-se uma melhora significativa nos produtos com maior valor agregado, ao passo que os setores intensivos em recursos naturais apresentaram piora.

A estrutura de participação relativa das exportaçōes e das importações mostrou-se, de certa forma, rígida para o Brasil e a Rússia, com continuidade do padrão exportador existente no início dos anos 2000. Ademais, o valor das importaçôes de produtos mais elaborados foi superior ao das exportaçōes, gerando uma pressão sobre os saldos comerciais, que permaneceram superavitários devido ao bom desempenho dos produtos menos elaborados. Tal fato caracteriza a estrutura de baixa qualidade do saldo comercial e a perda de dinamismo das exportaçóes nos produtos de alta intensidade tecnológica.

Já a estrutura dos indicadores de comércio internacional (MS, VCR e ICSC) não se modificou substancialmente para o Brasil e a Rússia, sendo que a tendência foi de aprofundamento do perfil de especialização existente no início dos anos 2000. Por outro lado, a China foi o país que apresentou modificaçóes relevantes para o período, convergindo para um padrão de especialização pautado em produtos de maior valor agregado. Além disso, também se observou uma concentração em um número menor de produtos para o Brasil e a Rússia, enquanto a China e a Índia passaram por uma maior diversificação na gama de produtos.

Em termos gerais, a avaliação é de que as estruturas do padrão de comércio do Brasil e da Rússia são basicamente de padrões de especialização do tipo ricardiano. Para o caso do Brasil, este padrão se viu reforçado não apenas pelo padrão histórico e pelas condições naturais do país, mas também pelo cenário internacional favorável, com elevação dos preços e da demanda internacional. Entretanto, faz-se importante a diversificação da pauta exportadora, pois esses produtos têm baixo grau de sofisticação, reduzido grau de oportunidade tecnológica e encadeamentos tecnológicos, além de baixo grau de geração de renda e expansão da demanda. 
Finalmente, nos casos da Índia e, principalmente, da China, o padrão de especialização foi constituído a partir de ganhos de eficiência schumpeteriana, pois a pauta de exportação destes países concentrou-se em produtos mais dinâmicos e de maior conteúdo tecnológico e, como visto anteriormente, os produtos com elevado teor tecnológico exprimem maior potencial de crescimento da elasticidade-renda da demanda internacional, conformando um padrão de eficiência simultaneamente schumpeteriano e kaldoriano.

\section{Referências bibliográficas}

ALMEIDA, M. Política industrial e crescimento. Radar Tecnologia, Produção e Comércio Exterior, n, 16, p. 47-56, out. 2011.

CARVALHO, V. R. D. S. Três ensaios sobre competitividade externa e desempenho econômico na década de 2000. 2010. Tese (Doutorado em Economia) - Departamento de Economia da Faculdade de Economia, Administração e Contabilidade, Universidade de São Paulo, São Paulo, 2010.

CAVALCANTE, L. R. Consenso difuso, dissenso confuso: paradoxos das políticas de inovação no Brasil. Radar Tecnologia, Produção e Comércio Exterior, abril 2011.

COMTRADE. United Nations Commodity Trade Statistics Database. 2013. Disponível em: <http://comtrade.un.org/db/>. Acesso em: jan. 2013.

CUNHA, A. M. A China e o Brasil na nova ordem internacional. Revista de Sociologia e Politica, Curitiba, v. 19, n. suplementar, p. 9-29, nov. 2011.

DOSI, G. Some notes on patterns of production, industrial organization and international competitiveness. In: MEETING ON "PRODUCTION REORGANIZATION AND SKILLS”. BRIE. Berkeley: University of California, September 10-12, 1987.

DOSI, G.; SOETE, L. Technology gaps and cost-based adjustment: some explorations on the determinants of international competitiveness. Metroeconomica, v. XXXV, n. 3, p. 197-222, October 1983.

DOSI, G.; PAVITT, K.; SOETE, L. The economics of technical change and international trade. Great Britain: Harvester Weatsheaf, 1990.

DOSI, G.; TYSON, L.; ZYSMAN, J. Trade, technologies, and development: a framework for discussing Japan. In: JOHNSON, C.; TYSON, L.; ZYSMAN, J. (Ed.). Politics and productivity: how Japan's development strategy works. New York: Harper Business, 1989. 
GUERRIERI, P. International competitiveness, trade integration and technological interdependence. In: BRADFORD JR., C. I. (Ed.). The new paradigm of systemic competitiveness: toward more integrated policies in Latin America. OECD, Development Centre Documents, 1994. HIRATUKA, C.; CUNHA, S. Qualidade e diferenciação das exportações brasileiras e chinesas: evolução recente no mercado mundial e na Aladi. Brasília: Ipea, junho 2011 (Texto para discussão, 1622).

IPEA. As transformaçōes estruturais do comércio exterior chinês. Comunicados do IPEA, n. $97,2011$.

LALL, S. The technological structure and perfomance of developing country manufactured exports, 1985-1998. Oxford: University of Oxford, 2000 (QEH Working Paper Series, 44).

LIBÂNIO, G. A. O comércio Brasil-China em perspectiva regional: análise e implicações para o desenvolvimento. In: XL ENCONTRO NACIONAL DE ECONOMIA - ANPEC, Anais... Porto de Galinhas: Anpec, 2012.

MARTINS, M. A. O comério exterior brasileiro nos anos de 1980 e 1990: estrutura e evolução do padrão de especialização. Campinas: Universidade Estadual de Campinas, 2004.

NEGRI, J. A. D. Preparando tecnologicamente a economia para o pós-crise. Radar Tecnologia, Produção e Comércio Exterior, junho 2009.

NEGRI, F. D.; ALVARENGA, G. V. A primarização da pauta de exportaçôes no Brasil: ainda um dilema. Radar Tecnologia, Produção e Comércio Exterior, abril 2011.

NEGRI, F. D.; PASSOS, M. C. A crise e o padrão de especialização comercial brasileira. Radar Tecnologia, Produção e Comércio Exterior, junho 2009. 